\title{
Cytoplasmic CD3 Positive
}

National Cancer Institute

\section{Source}

National Cancer Institute. Cytoplasmic CD3 Positive. NCI Thesaurus. Code C162086.

An indication that cytoplasmic expression of the CD3 complex has been detected in a sample. 